\title{
Analysis on the Difficulties and Realistic Paths of Orientation Training Rural Teachers in China
}

\author{
Wanli Teng ${ }^{1, *}$ Xia Jiang ${ }^{2}$
}

\author{
${ }^{1}$ School of Danyang Teachers, Zhenjiang College, Zhenjing, Jiangsu 212000, China \\ ${ }^{2}$ School of Educational Science, Yangzhou University, Yangzhou, Jiangsu 225000, China \\ *Corresponding author. Email: jsjqxtwl227@163.com
}

\begin{abstract}
The orientation training rural teachers is the key to the construction of rural teachers, not only to ensure the locality of rural teachers, but also to promote the professionalism of rural teachers. However, based on the analysis of the three dimensions of the supply side, the demand side and the use side in the orientation training rural teachers, there is a contradiction between the supply of normal colleges and the demand of rural schools, and a deviation between the working environment of rural schools and the professional expectations of normal students. Therefore, the government should focus on local cultural education, and accurately create "one specialization, multiple capabilities" generaldisciplinary rural teachers; at the same time, the government should also improve the welfare of rural teachers, and increase support for rural teachers' professional development, in order to accurately implement the targeted training policy for rural teachers.
\end{abstract}

\section{Keywords: rural teachers, orientation training, difficulties, realistic paths}

\section{INTRODUCTION}

In order to promote the development of rural education, the State Council promulgated the "Rural Teacher Support Plan (2015-2020)" (hereinafter referred to as the "Support Plan") in June 2015, which clearly pointed out that targeted training is the main way to supplement the rural teacher team. Orientation training rural teachers refers to the selection of rural teacher candidates who meet the relevant conditions through contracts, entrust the training of designated colleges and universities, and assign them to the rural schools where the students are sourced for a certain number of years after graduation. The orientation teacher students will teach in the countryside after graduation, whether they can serve the rural education cause for a long time, and whether they are competent for the work of rural teachers. These have become the close attention of education researchers and education managers. Based on the three dimensions of supply side, demand side and use side, this paper discusses the realistic dilemma and solution of the orientation

*Fund: This article is a preliminary research result of the 2015 Youth Fund Project of the Ministry of Education's Humanities and Social Science Research Program "Research on the Operational Guarantee Mechanism of Urban 'Public' Kindergartens in the Context of Quality Improvement" (Project Number: 15YJC880029); Zhenjiang College 2019 Youth Special Research Program "Research on the System Dilemma and Countermeasures of the Safety Management of Private Kindergartens" (Project Number: GZQNZX201903). training of rural teachers, and provides references for the precise implementation of the orientation training policy rural teachers and the solution of the demand for teachers in rural schools.

\section{SigNifiCANCE}

\section{A. Ensuring the locality of rural teachers}

Locality is the background color of our country's rural teachers. The "Support Plan" regards "getting down, keeping, and teaching well" as an important goal for the construction of rural teachers. Judging from the educational experience of secondary normal schools, secondary normal schools have cultivated rural primary school teachers who are familiar with their hometowns. Although the conditions for running rural schools were poor at the time, most of the normal school graduates were able to return to their hometowns to teach and stick to the front line of rural education. Drawing lessons from secondary normal education, nearly half of the provinces have implemented a policy of orientation training of rural teachers, selecting outstanding students with rural household registration, and highlighting the rural characteristics of rural teachers. Based on similar cultural background, living habits, and blood relationship, these rural teachers who came from the countryside and returned to the countryside have an innate sense of identity with the countryside. As one study showed, "Teachers in their hometowns are familiar with the local customs, speak the local dialect, accept rural life, understand the life experience and 
situation of rural children and adolescents, and can maintain familiar relationships and frequent interactions with their parents". If these native rural teachers work in a foreign country, then they have familiarity with the local people and hometown. Cultural capitals such as dialects no longer exist. It can be said that the orientation training of rural teachers has ensured the locality of rural teachers to a certain extent.

\section{B. Promoting the professionalism of rural teachers}

"Teaching well with high quality" is the ultimate goal of orientation training of rural teachers. The key to meeting such specifications lies in training "one specialization, multiple abilities" general-disciplinary rural teachers. In the experience of cultivating rural teachers in secondary normal education, the most important thing is to offer diversified courses, including compulsory courses and elective courses, so as to provide students with as many choices as possible so that they can learn about various subjects. In addition, activity courses including calligraphy, painting, and vocal music are also set up. The international experience of colleges and universities has proved that whether it can adapt to multi-subject teaching and whether it can cross-disciplinary teaching has become a watershed for judging outstanding teachers and ordinary teachers. Taking Hunan First Normal University as an example, the orientation teachers graduated from 2011 to 2017 have taken up teaching positions in local rural schools, and the general teachers trained by the school have injected fresh blood into rural schools. As the number of classes and the total number of courses in rural schools have not decreased significantly, general teachers who can handle the teaching model of "small classes" and "packaged classes" have become scarce resources in rural primary schools. The supplement of training general teachers has eased the shortage of teachers in rural schools to a certain extent. More importantly, compared with ordinary teachers, teachers with this standard have a higher level of professional development and better professional quality.

\section{MAIN DIFFICULTIES}

The orientation training rural teachers, as a supplementary mechanism for rural teachers of "oriented enrollment, oriented training and oriented employment" in the new era, has better assisted the development of rural education. However, in the process of orientation training rural teachers, there are some problems on the supply side, demand side, and use side. First of all, the supply side refers to normal colleges. The challenge it faces is that the targeted teacher students trained by normal colleges cannot meet the needs of rural education and cannot be fully qualified for the work of rural teachers. Secondly, the demand side refers to rural schools. The limitations of material and spiritual conditions in rural schools cannot attract talents for discussion. Finally, the use side is the gap between the high expectations of teachers' professional students and the realistic working environment of rural schools.

\section{A. A contradiction between the supply of normal colleges and the demand of rural schools}

As the supplier of the orientation training rural teachers, normal colleges are good at using the "universal theory of cultivating higher education", ignoring the peculiarities of teacher training in the countryside after graduation. Scholar Chen Shijian pointed out, "Today's teacher education system is strictly urban teacher education. Most of the teachers we trained are integrated into the city. Even if they go to the countryside, they will not stick to the countryside." Few normal colleges consider training teachers who can specifically serve the cause of rural teachers, especially long-term service in rural areas. For example, most of the internship practices of normal students are selected in urban schools, and rural schools are rarely considered in the construction of practice bases. "Universal" is only the basic requirement of teacher education, but can teachers who only have this condition work in the countryside? Can you adapt after working in the countryside? These specific issues should be paid attention to by normal colleges that train rural teachers.

On the one hand, through the four-year city-oriented higher education, the teacher training students are affected by the big environment of the city for a long time, and naturally, a certain degree of city-oriented employment is formed. In this context, if normal students choose to leave the city to work in the countryside after graduation, they will suffer serious "unacceptable". Therefore, in the process of choosing a career, the orientation normal students would rather violate the employment agreement signed before enrollment and give up working in the countryside. The People's Daily conducted a survey on the employment status of the first free teacher-training students in 2011 and found that only $4.1 \%$ of the graduates went to the countryside. Among them, none of the ten provinces and regions including Gansu and Qinghai had a oriented teacher-training graduate standing on the podium of a rural school. On the other hand, from the perspective of the needs of rural schools, they can adapt to the "one specialization, multiple capabilities" normal students are currently the most popular in rural primary and secondary schools. In a survey study on "What kind of college students are needed in rural primary and secondary schools in western China", 81 principals participating in the study reported that at present, most rural primary schools do not have professional teachers in the music, physical, and aesthetic courses, and can only be Other teachers substitute lessons and cannot teach normally. They hope that universities can train 
more teachers who are suitable for rural education, and The contradiction is that there is no difference between the training of oriented normal students and ordinary normal students in normal colleges, and the "subject theory goal + teacher skill goal" is simply classified as the training goal of oriented normal students. Therefore, the current oriented teacher students may not meet the needs of rural schools.

\section{B. A deviation between the working environment of rural schools and the professional expectations of normal students}

Education is an investment in human capital. Oriented normal students will fully consider the human capital accumulated in the four years of higher education, and have subjective intentions about their employment location, level of welfare benefits, and career development space. In fact, what contradicts the future career expectations of targeted teacher students is: there is a clear gap between the expected career wages and the actual wages of rural teachers. Yue Kui and Wang conducted a survey on the employment intentions of free teacher students in 2011. Regarding the expectation of free teacher students for their work benefits, $76.7 \%$ of the free teacher students surveyed expected their salary after graduation in "2000". Above RMB", $19.6 \%$ of the free teacher students expect the salary to be " 1500 to $2000 \mathrm{RMB}$ ". In the actual work of rural teachers, according to Luo Ruguo's survey of rural teachers' salary income, $72.8 \%$ of the teachers surveyed were rural teachers with an average monthly income of between 1,000 yuan and 2,000 yuan, and 5.8\% of the teachers' average monthly income was Between 2,000 and 3,000 yuan, teachers with an average monthly income of between 3,000 and 4,000 yuan accounted for $0.6 \%$ of the total number of teachers surveyed, and another $20.6 \%$ of teachers had a monthly income below 1,000 yuan. It can be seen that the professional expectations of normal students are much higher than the average income level of rural teachers.

In addition, the professional development expectations of normal students deviate greatly from the actual development of rural teachers. In addition to the consideration of material conditions such as salary income and welfare benefits, normal students pay more attention to future personal development, and pay more attention to the combination of their own majors, development prospects and professional status. However, in reality, normal students face the awkward situation of "no development". One is the lack of opportunities for post-employment training for targeted normal students. Since rural schools are basically smallscale schools, it is more common for one person to do multiple subjects at the same time. It is impossible to allow teachers to leave to participate in relevant training. Even though much training is now being carried out in the form of online training, teachers have no time to learn training courses due to heavy teaching tasks and even occupy their spare time. The second is that the promotion space for oriented normal students is narrow. Although the national professional title evaluation regulations are inclined to rural teachers, the current conditions for the evaluation of professional titles of rural teachers and urban teachers are almost the same. The teacher's education and teaching performance is the main evaluation index, and the education and teaching performance is reflected in the academic performance of the students taught. In a rural environment where the student base is relatively weak and parents do not pay much attention to it, it is difficult for rural teachers to achieve themselves through students like urban teachers, which further hinders their development.

\section{REALISTIC PATHS}

The orientation training rural teachers is facing a real dilemma, which needs to be solved from the system level. If the orientation training rural teachers is compared to a concentric circle, the main body of rural teachers is the center of the concentric circle, and the peripheral support provided by the system is distributed in the garden and outside the center of the circle. The focus is to provide rural teachers with a A sustainable environment. In this way, rural teachers can achieve internal growth in a secure and supportive external environment, and then promote the construction of rural teachers.

\section{A. Creating "one specialization, multiple capabilities" general-disciplinary rural teachers}

At present, the training of targeted normal students in normal colleges is mainly based on the urban teacher education model. To this end, it is necessary to strengthen the local culture education for oriented teacher students. First, based on the selection criteria of the source of students, the government should carefully review the students' early family situation, life background, psychological quality, and professional vision, and select talents that are truly suitable for rural teachers. Second, when enrolling in education, teachers should fully understand the current status of rural education development, and awaken their sense of social responsibility and local feelings. Third, it is necessary to formulate training programs suitable for rural teachers. Whether the training plan is scientific and reasonable is a key part of building a team of highquality rural teachers. Finally, and most importantly, it is necessary to expand the diversity of the majors taught by normal students, to enable students to develop from specificity to diversity, and from specificity to versatility. In other words, while arranging general courses, some special courses on rural local knowledge can be added. On the premise of fully mastering the 
basic knowledge, cultivate excellent teachers with "one specialization, multiple abilities".

\section{B. Improving the welfare of rural teachers, increasing support for rural teachers' professional development}

According to Maslow's hierarchy of needs theory, the most fundamental need of human beings is the physical need, which is the cornerstone of selfrealization. As a "rational person", rural teachers will pay attention to their professional development only after the material conditions such as salary income and welfare benefits are basically met. Therefore, government funding at all levels should be increased to ensure that rural teachers receive considerable wage income. For example, the southern area of Jiangsu Province appropriately adjusted the subsidy standards for rural teachers, and offered salary increases to rural teachers who have taught for 5 years or more. This solved the housing problem of rural teachers and eased the economic pressure on rural teachers to a certain extent. Second, the government should increase support for the professional development of rural teachers, create more opportunities for rural teachers to go out for training and learning, so as to broaden the professional development space of rural teachers. Taking into account the heavy workload of rural teachers, the Education Bureau of Zhenjiang City, Jiangsu Province piloted an urban-rural school paired assistance system in Runzhou District, requiring excellent teachers from urban schools to be selected for exchanges with rural schools, and rural schools to send rural teachers to urban schools for further training. The specific approach is: urban and rural schools sign assistance agreements to boost rural teachers' teaching level through bundled assessment.

\section{CONCLUSION}

This research analyzes the necessity of orientation training of rural teachers and the practical difficulties they face. The difficulties are that the targeted teacher students trained by normal colleges cannot meet the needs of rural education and cannot be fully qualified for the work of rural teachers. In the second place, the demand side refers to rural schools. The limitations of material and spiritual conditions in rural schools cannot attract talents for discussion. In the end, the use side is the gap between the high expectations of teachers' professional students and the realistic working environment of rural schools. If the orientation training rural teachers is compared to a concentric circle, the main body of rural teachers is the center of the concentric circle, and the peripheral support provided by the system is distributed in the garden and outside the center of the circle. In this regard, it is urgent to solve the problem from the system level. On the one hand, we should strengthen the local cultural education for teacher students and select talents who are truly suitable for the work of rural teachers; on the other hand, we should improve the welfare of rural teachers, including salary income and welfare benefits. Only after the basic material conditions are met, will they pay attention to their professional development.

\section{References}

[1] Wang Yanling, and Chen Xiangming, "Return to the countryside: the path choice for the construction of rural teachers in my country," Educational Development Research, vol. 39, pp.29-36, August 2019

[2] Zhang Songxiang, "Localization: The Only Way to Train the Contingent of Rural Teachers in my country," Journal of China Education, vol. 37, pp.62-68, December 2016

[3] Sun Qingling, Experts take the pulse to crack the "embarrassment" of rural teachers, China Youth Daily, vol. 67 October 2017.

[4] Wu Qiqiang, Where did the first free teacher training students go, People's Daily, vol. 64, September 2011

[5] Gong Lihua, What kind of college students do rural primary and secondary schools in western China need? - Based on the survey and thinking of 181 rural primary and secondary school principals in Gansu Province, Shanghai Educational Research vol.29, pp.10-13, May 2009.

[6] Yue Kui, and Wang Jing, Employment Conflicts and Avoidance of Free Normal Students - Based on an Analysis of a Survey of Free Normal Students' Employment Intentions, Educational Research and Experiment, vol.29, pp.32-35, February 2011.

[7] Luo Ruguo, and Wang Shanshan, Survey and Thinking on Satisfaction of Teachers' Salary Income in Primary and Secondary Schools, Modern Education Management, vol.31, pp.75-78, May 2011. 